\title{
Cystathionine-gamma-lyase inhibitor attenuates acute lung injury induced by acute pancreatitis in rats
}

Zhen $\mathrm{Qu}^{1}$, Yong Jiang ${ }^{2}$, Bao-Qiang Wu², Yun-Fei Duan², Zhen-Di Sun², Guang-Hua Luo ${ }^{2}$

'Department of General Surgery, Tumor Hospital, Fourth Affiliated Hospital of Soochow University, Changzhou, Jiangsu Province, P.R. China

${ }^{2}$ Department of Hepatobiliary Surgery, Changzhou $1^{\text {st }}$ People's Hospital, Third Affiliated Hospital of Soochow University, Changzhou, Jiangsu Province, P.R. China

Submitted: 22 January 2013

Accepted: 28 April 2013

Arch Med Sci 2014; 10, 4: 825-829

DOI: 10.5114/aoms.2014.44873

Copyright $\odot 2014$ Termedia \& Banach

\section{Abstract}

Introduction: Acute pancreatitis (AP) is known to induce injuries to extrapancreatic organs. Because respiratory dysfunction is the main cause of death in patients with severe AP, acute pancreatitis-associated lung injury (APALI) is a great challenge for clinicians. This study aimed to investigate the potential role of hydrogen sulfide $\left(\mathrm{H}_{2} \mathrm{~S}\right)$ in the pathogenesis of APALI.

Material and methods: Fifty-four SD rats were randomly divided into three groups: the AP group of rats that received injection of sodium deoxycholate into the common bile duct, the control group that underwent a sham operation, and the treatment group made by intraperitoneal injection of propargylglycine (PAG), an inhibitor of cystathionine- $\gamma$-lyase (CSE), into rats with AP. Histopathology of the lung was examined and the expression of CSE and TNF- $\alpha$ mRNA in lung tissue was detected by real-time polymerase chain reaction. The $\mathrm{H}_{2} \mathrm{~S}$ level in the serum was detected spectrophotometrically. Results: The serum concentration of $\mathrm{H} 2 \mathrm{~S}$ and CSE and TNF- $\alpha$ expression in the lung were increased in AP rats modeled after $3 \mathrm{~h}$ and $6 \mathrm{~h}$ than in control rats $(p<0.05)$. Intraperitoneal injection of PAG could reduce the serum concentration of $\mathrm{H}_{2} \mathrm{~S}$, reduce CSE and TNF- $\alpha$ expression, and alleviate the lung pathology $(p<0.05)$.

Conclusions: Taken together, our findings suggest that the $\mathrm{H}_{2} \mathrm{~S} / \mathrm{CSE}$ system is crucially involved in the pathological process of APALI and represents a novel target for the therapy of APALI.

Key words: acute pancreatitis associated lung injury, hydrogen sulfide, propargylglycine.

\section{Introduction}

Acute pancreatitis (AP) is a frequent disease of the pancreas and is mainly diagnosed by acute abdominal pain accompanied by increased levels of serum amylase and lipase. Although mild acute pancreatitis has a low mortality rate, severe acute pancreatitis (SAP) is a fatal pathogenetic condition and accounts for a high mortality rate in China [1]. Notably, SAP-induced pathological changes are not limited to the pancreas. It is well known that SAP also induces injuries to extrapancreatic organs, such as the lung, liver and kidney, leading to multiple organ failure and even death [2, 3]. Because respiratory dysfunction is the main cause of death in patients with SAP, acute pancreatitis-associated lung injury (APALI) is a great challenge for cli-

\author{
Corresponding author: \\ Assoc. Prof. Jiang Yong MD, \\ $\mathrm{PhD}$ \\ Department \\ of Hepatobiliary Surgery \\ Third Affiliated Hospital \\ of Soochow University \\ Changzhou, 213003 \\ Jiangsu Province, China \\ Phone: +86 51968871341 \\ E-mail: \\ yjiang8888@hotmail.com
}


nicians. Unfortunately, the molecular mechanism of APALI remains elusive.

Hydrogen sulfide $\left(\mathrm{H}_{2} \mathrm{~S}\right)$ plays an important role in the pathogenesis of AP [4]. Hydrogen sulfide is synthesized from L-cysteine via the action of cystathionine- $\gamma$-lyase (CSE) and cystathionine- $\beta$-synthase (CBS). Hydrogen sulfide acts as an important mediator of inflammation and CSE is the main enzyme involved in $\mathrm{H}_{2} \mathrm{~S}$ formation in the pancreas [5].

In the present study we aimed to investigate the potential role of $\mathrm{H}_{2} \mathrm{~S}$ and $\mathrm{CSE}$ in the pathogenesis of APALI. We established a rat AP model and examined the expression of CSE in lung tissue and the level of $\mathrm{H}_{2} \mathrm{~S}$ in the serum. Furthermore, we analyzed the correlation of $\mathrm{H}_{2} \mathrm{~S}$ and CSE levels with the pathological lung changes and the level of the inflammatory cytokine tumor necrosis factor- $\alpha$ (TNF- $\alpha$ ).

\section{Material and methods}

\section{Animals}

A total of 54 healthy male Sprague-Dawley rats (weight 250-300 g) were purchased from the Experimental Animal Center of Jiangsu University. They were randomly divided into three groups with 18 rats in each group: the control group; the AP group; and the intervention group. The rats in the AP group were established as an AP model by the injection of $3 \%$ sodium deoxycholate $(0.1 \mathrm{ml} / 100 \mathrm{~g}$ body weight) into the pancreas with injection velocity of $0.2 \mathrm{ml} / \mathrm{min}$. The rats in the control group were subjected to a sham operation. The rats in the intervention group were AP rats subjected to intraperitoneal injection of propargylglycine (PAG, CSE inhibitor). The protocols were approved by the Animal Care and Use Committee of the Third Affiliated Hospital of Suzhou University, Changzhou, Jiangsu.

\section{Histopathology analysis}

The histopathology of rat lung tissue was analyzed as described previously. Five fields and two lobes were examined in each rat by a pathologist under light microscopy after the tissues were fixed with $10 \%$ formalin, embedded in paraffin and subjected to HE staining. On histopathologic examination, pulmonary injury was graded into four categories, as follows: grade 0, no diagnostic change; grade 1 , mild neutrophil leukocyte infiltrations and mild to moderate interstitial congestion; grade 2, moderate neutrophil leukocyte infiltrations, perivascular edema formation, and partial destruction of pulmonary architecture; and grade 3, dense neutrophil leukocyte infiltration and complete destruction of the pulmonary architecture. Severity of none, mild, moderate and severe was scored as $0,1,2$, and 3, respectively [6].

\section{Real-time polymerase chain reaction}

Total RNA was extracted from lung tissue by TRIzol and used to synthesize cDNA. cDNA was then used as the template for PCR with the following primers: CSE forward: 5'-GTGATGTTGTCATGGGCTTAGT-3' and reverse: 5'-TCGGCAGCAGAGGTAACAA-3'. TNF- $\alpha$ forward: 5'-CACCACGCTCTTCTGTCTACTG-3' and reverse: 5'-GCTTGGTGGTTTGCTACGAC-3'. Glyceraldehyde-3-phosphate dehydrogenase (GAPDH) was used as a normalization control: forward: 5'-AAGCTGGTCATCAATGGCAAAC-3' and reverse 5'-GAAGACGCCAGTAGACTCCACG-3'.

The reaction conditions were as follows: $94^{\circ} \mathrm{C}$ for $25 \mathrm{~s}$, then 40 cycles of $64^{\circ} \mathrm{C}$ for $25 \mathrm{~s}, 72^{\circ} \mathrm{C}$ for $30 \mathrm{~s}$, and a final extension at $72^{\circ} \mathrm{C}$ for $5 \mathrm{~min}$.

Relative CSE or TNF- $\alpha$ expression was measured by the comparative CT method ( $\Delta \Delta \mathrm{CT}$ method; Applied Biosystems) using glyceraldehyde-3-phosphate dehydrogenase (GAPDH) RNA as an internal standard. In this method, the threshold cycle (CT) indicates the fractional cycle number at which the amount of amplified target reaches a fixed threshold. The $\Delta C T$ value was determined by subtracting the average GAPDH CT value from the average CSE or TNF- $\alpha$ CT value. The calculation of $\Delta \Delta C T$ involves subtraction by the $\triangle \mathrm{CT}$ baseline sample. The amount of target, normalized to GAPDH and relative to the baseline sample, is given by $2-\Delta \Delta C T$. The resulting $\triangle \Delta C T$ factor enables relative quantification of the RNA of interest.

\section{Measurement of plasma hydrogen sulfide}

Plasma level of $\mathrm{H}_{2} \mathrm{~S}$ was measured spectrophotometrically as previously described [7]. We collected blood at $3 \mathrm{~h}, 6 \mathrm{~h}$ and $12 \mathrm{~h}$ after rats were modeled. Once blood was drawn into plastic Vacutainers using EDTA ( $1 \mathrm{mg} / \mathrm{ml}$ of blood), plasma was immediately obtained through brief ( $\left.3^{\prime}\right)$ centrifugation at $3000 \mathrm{~g}$ and rapidly added to the assay mixture. The $\mathrm{H}_{2} \mathrm{~S}$ concentration was measured spectrophotometrically as follows: in a test tube containing $0.5 \mathrm{ml}$ of $1 \%$ zinc acetate, $0.4 \mathrm{ml}$ of $\mathrm{FeCl}_{3}$ in $0.4 \mathrm{ml}$ of $\mathrm{HCl}$ and $0.5 \mathrm{ml}$ of $\mathrm{N}, \mathrm{N}$-dimethyl-p-phenylenediamine dihydrochloride $\left(\mathrm{C}_{8} \mathrm{H}_{12} \mathrm{~N}_{2}\right)$ in $20 \mathrm{ml}$ of $\mathrm{HCl} 7.2 \mathrm{~mol} / \mathrm{l}, 0.4 \mathrm{ml}$ of plasma were added. To deproteinize the sample, $1 \mathrm{ml}$ of a $10 \%$ solution of trichloroacetic acid was added, and then the mixture was centrifuged at $4000 \mathrm{~g}$ for $5 \mathrm{~min}$ at room temperature. The absorbance of the supernatant was read at $665 \mathrm{~nm}$ wavelength. Standard curves were repeated daily with triplicate measurement for each point, and freshly made solutions were utilized at all times.

\section{Statistical analysis}

Values were presented as mean and standard deviation. The significance of differences between 


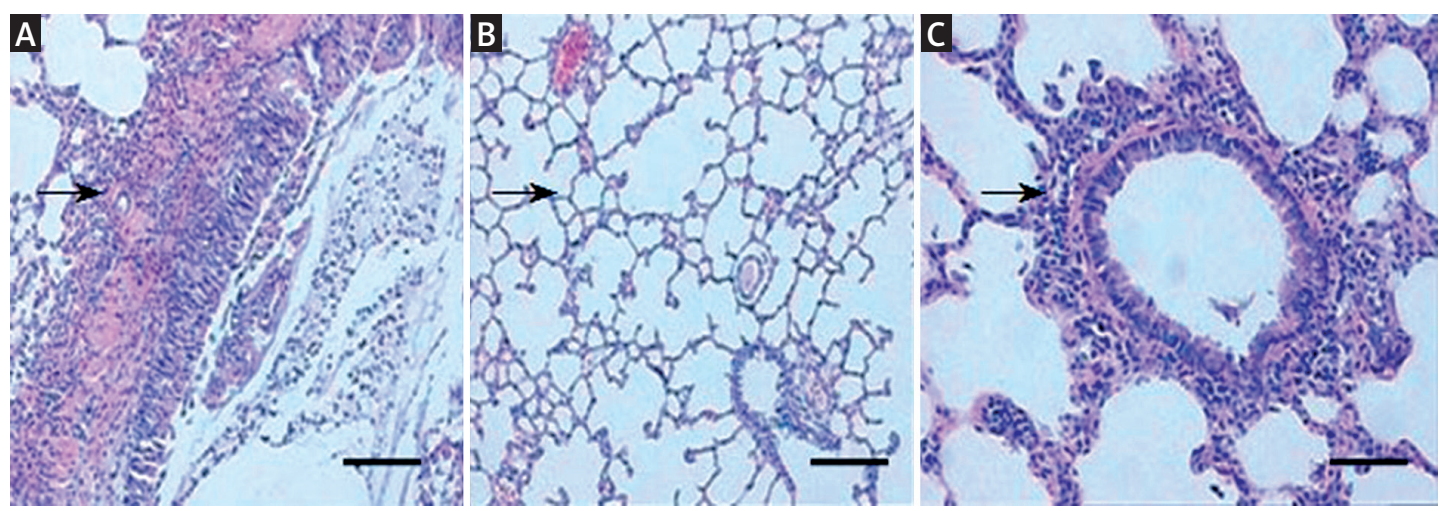

Figure 1. Histopathology of lung tissue of different groups of rats. A - In AP rats, the lung tissue showed a significantly wider alveolar septum, and a large number of infiltrated white blood cells. B - In control rats, the lung tissue was normal. C - After PAG treatment, the pulmonary interstitial edema, alveolar exudation, and bleeding were significantly decreased. Arrows indicate white blood cells. Bar: $100 \mu \mathrm{M}$

Table I. Histopathology score of the lungs of each group of rats

\begin{tabular}{|lcccc|}
\hline Groups & $\begin{array}{c}\text { Pulmonary interstitial } \\
\text { edema }\end{array}$ & $\begin{array}{c}\text { Exudation of } \\
\text { inflammatory cells }\end{array}$ & Alveolar bleeding & Alveolar edema \\
\hline Control & $0.33 \pm 0.07$ & $0.20 \pm 0.02$ & $0.10 \pm 0.02$ & $0.13 \pm 0.02$ \\
\hline AP & $2.58 \pm 0.21^{\Delta}$ & $2.76 \pm 0.27^{\Delta}$ & $1.13 \pm 0.11^{\Delta}$ & $2.13 \pm 0.11^{\Delta}$ \\
\hline PAG & $1.56 \pm 0.25^{\star}$ & $2.21 \pm 0.35$ & $0.53 \pm 0.05^{\star}$ & $1.87 \pm 0.05^{*}$ \\
\hline
\end{tabular}

${ }^{\Delta} p<0.05, A P$ vs. control, ${ }^{*} p<0.05, P A G$ vs. AP

two groups was determined by Student's $t$-test. A $p$ value of less than 0.05 was considered statistically significant. All statistical analyses were conducted using SPSS version 12 (SPSS Inc., Chicago, IL, USA).

\section{Results}

Propargylglycine treatment alleviates the pathology of lung injury in acute pancreatitis rats

Histopathology analysis showed that $12 \mathrm{~h}$ after establishing the AP model, purple-brown areas of lung atelectasis were observed in the rat lung

Table II. CSE mRNA expression in each group of rats

\begin{tabular}{|lccc|}
\hline Groups & $3 \mathrm{~h}$ & $6 \mathrm{~h}$ & $12 \mathrm{~h}$ \\
\hline Control & $0.51 \pm 0.19$ & $0.76 \pm 0.18$ & $0.35 \pm 0.09$ \\
\hline AP & $1.29 \pm 0.06^{\Delta}$ & $2.64 \pm 0.61^{\Delta}$ & $0.59 \pm 0.30$ \\
\hline PAG & $0.81 \pm 0.32^{\star}$ & $1.47 \pm 0.44^{\star}$ & $0.56 \pm 0.37$ \\
\hline
\end{tabular}

${ }^{\Delta} p<0.05$, AP vs. control, ${ }^{*} p<0.05$, PAG vs. AP

Table III. TNF- $\alpha$ mRNA expression in each group of rats

\begin{tabular}{|lccc|}
\hline Groups & $3 \mathrm{~h}$ & $6 \mathrm{~h}$ & $12 \mathrm{~h}$ \\
\hline Control & $0.61 \pm 0.38$ & $0.76 \pm 0.18$ & $0.45 \pm 0.21$ \\
\hline AP & $1.25 \pm 0.26^{\Delta}$ & $2.64 \pm 0.61^{\Delta}$ & $1.32 \pm 0.39^{\Delta}$ \\
\hline PAG & $1.21 \pm 0.16$ & $1.91 \pm 0.40^{\star}$ & $1.23 \pm 0.28$ \\
\hline
\end{tabular}

${ }^{\Delta} p<0.05$, AP vs. control, ${ }^{*} p<0.05$, PAG vs. AP specimen. In addition, the lung tissue showed a significantly wider alveolar septum, and a large number of infiltrated white blood cell (Figure $1 \mathrm{~A}$ ). In contrast, the lung tissue was normal in the control group (Figure $1 \mathrm{~B}$ ). Propargylglycine treatment significantly improved the pathology in the SAP group in that although inflammatory cells infiltrated the alveolar septal, the pulmonary interstitial edema, alveolar exudation, and bleeding were significantly decreased (Figure $1 \mathrm{C}$ ). The detailed pathological scores of lung injury in the 3 groups of rats are shown in Table I.

Propargylglycine treatment reduces cystathionine-g-lyase and tumor necrosis factor- $\alpha$ expression in the lung tissue of acute pancreatitis rats

RT-PCR analysis showed that the expression of both CSE and TNF- $\alpha$ at the mRNA level was significantly higher in the lung tissue of AP rats modeled after $3 \mathrm{~h}$ and $6 \mathrm{~h}$ than in control rats $(p<0.05)$. In AP rats modeled after $12 \mathrm{~h}$, CSE mRNA expression in the lung was not significantly increased compared to control rats, but TNF- $\alpha$ mRNA expression was significantly higher than control rats $(p<0.05)$ (Tables II and III).

On the other hand, treatment with PAG reduced CSE mRNA expression in the lung of AP rats modeled after $3 \mathrm{~h}$ and $6 \mathrm{~h}(p<0.05)$ and reduced TNF- $\alpha$ mRNA expression in the lung of AP rats modeled after $6 \mathrm{~h}(p<0.05)$ (Tables II and III). 
Table IV. Serum concentration of $\mathrm{H}_{2} \mathrm{~S}$ in each group of rats $(\mu \mathrm{mol} / \mathrm{l})$

\begin{tabular}{|cccc|}
\hline Groups & $3 \mathrm{~h}$ & $6 \mathrm{~h}$ & $12 \mathrm{~h}$ \\
\hline Control & $24.18 \pm 1.63$ & $23.79 \pm 1.81$ & $23.89 \pm 1.18$ \\
\hline AP & $30.34 \pm 1.40^{\Delta}$ & $37.97 \pm 1.56^{\Delta}$ & $31.57 \pm 3.17^{\Delta}$ \\
\hline PAG & $29.53 \pm 2.63$ & $30.73 \pm 2.32^{\star}$ & $24.38 \pm 2.29^{\star}$ \\
\hline
\end{tabular}

${ }^{\Delta} p<0.05$, AP vs. control, ${ }^{*} p<0.05$, PAG vs. AP

Propargylglycine treatment reduces serum hydrogen sulfide concentration in acute pancreatitis rats

Analysis of serum $\mathrm{H}_{2} \mathrm{~S}$ concentration in the 3 groups of rats showed that serum $\mathrm{H}_{2} \mathrm{~S}$ concentration was higher in AP rats than in control rats $(p<0.05)$. After PAG treatment serum $\mathrm{H}_{2} \mathrm{~S}$ concentration was significantly decreased in AP rats $(p<0.05)$ (Table IV).

\section{Discussion}

Acute pancreatitis is a common clinical acute $a b$ domen with high mortality. About $1 / 3$ of AP patients develop complications associated with lung injury or acute respiratory distress syndrome (ARDS), and $60 \%$ of AP patients with lung injury or ARDS die within 1 week. However, AP associated lung injury in the pathogenesis remains uncertain. In recent years many experimental studies have shown that AP-induced lung injury is a systemic inflammatory response syndrome in the lung. However, the pathogenesis of APALI is still poorly understood.

Gases such as nitric oxide (NO) and carbon monoxide (CO) play an important role in a variety of pathophysiological processes. Recent evidence suggests that $\mathrm{H}_{2} \mathrm{~S}$ is a new family of endogenous gaseous molecules [8]. Hydrogen sulfide is synthesized from L-cysteine via the action of three enzymes: CBS, CSE and 3-mercaptopyruvate sulfur transferase (MST). Hydrogen sulfide formation in the cardiovascular system is mainly catalyzed by CSE, while CBS plays an important role in the brain. In contrast, MST down-regulates $\mathrm{H}_{2} \mathrm{~S}$ formation to a much extent [9].

Hydrogen sulfide has been shown to exhibit various pathophysiological effects, including the following: (1) vascular smooth muscle relaxation. CSE and $\mathrm{H}_{2} \mathrm{~S}$ synthase are expressed in the pulmonary artery, aorta, tail artery, mesenteric artery, portal vein and other blood vessel wall tissue [10-13]; (2) induction of apoptosis. NaHS $\left(\mathrm{H}_{2} \mathrm{~S}\right.$ donor) induces the apoptosis of lung fibroblasts in a dose-dependent manner. In hypoxic condition, $\mathrm{H}_{2} \mathrm{~S}$ can inhibit Bcl22 protein expression and increase the expression of Fas and caspase-specific protease 23, thus inducing the apoptosis of pulmonary artery smooth muscle cells [14]; (3) anti-platelet aggregation: platelet aggregation can be inhibited by NaHS. It is speculated that $\mathrm{H}_{2} \mathrm{~S}$ might reduce the number of disulfide bonds in key proteins involved in platelet activation [15]; (4) inflammatory response: in a variety of animal disease models, $\mathrm{H}_{2} \mathrm{~S}$ induces the expression of nuclear factor- $\kappa \mathrm{B}$ $(\mathrm{NF}-\kappa \mathrm{B})$, interleukin (IL)-1 $\beta$, IL-2, tumor necrosis factor (TNF)- $\alpha$, leukocyte chemoattractant protein-1, macrophage inflammatory protein-2 and P substances in the liver and lung [16]; (5) stimulation of angiogenesis. Exogenous $\mathrm{H}_{2} \mathrm{~S}$ promotes vascular endothelial cell growth, metastasis, repair of mechanical injury and formation of tubular structures in a concentration-dependent manner (10-20 $\mu \mathrm{mol} / \mathrm{l})$ [17].

Currently, the contribution of $\mathrm{H}_{2} \mathrm{~S}$ to the development of APALI remains controversial. In a lipopolysaccharide (LPS)-induced acute lung injury (ALI) model it was found that $\mathrm{H}_{2} \mathrm{~S}$ concentrations in plasma and lung tissue were decreased and CSE activity in lung tissue also declined [18]. Another study on an ALI model showed that the endogenous $\mathrm{CSE} / \mathrm{H}_{2} \mathrm{~S}$ system was involved in oleic acid-induced pathophysiology of ALI [19]. In contrast, Li et al. reported that $\mathrm{H}_{2} \mathrm{~S}$ and TNF- $\alpha$ levels in plasma and myeloperoxidase activity in lung tissue were increased in an ALI model compared with a normal control group. Furthermore, PAG could alleviate lung injury and reduce $\mathrm{H}_{2} \mathrm{~S}$ and TNF- $\alpha$ levels in plasma and myeloperoxidase activity in lung tissue [20]. In an AP mouse model, PAG treatment significantly reduced pancreatic CSE mRNA expression and activity and serum concentration of $\mathrm{H}_{2} \mathrm{~S}$. Moreover, it reduced myeloperoxidase (MPO) activity in the lung tissue and effectively reduced the pulmonary inflammation and injury [21]. Furthermore, their levels (according to the results of Tables II and III) are still higher compared to control rats, which may suggest that $\mathrm{H}_{2} \mathrm{~S}$ promotes the pathogenesis of APALI, and PAG $\left(\mathrm{H}_{2} \mathrm{~S} / \mathrm{CSE}\right.$ inhibitor) administration can effectively reduce the pulmonary inflammation and injury, but $\mathrm{H}_{2} \mathrm{~S}$ is only a member of endogenous gaseous molecules family which includes NO and CO. Its inhibition may eliminate the inflammatory response partially, instead of completely.

In the present study, we observed that in AP rats modeled after $3 \mathrm{~h}$ and $6 \mathrm{~h}$, the relative mRNA expression levels of CSE and TNF- $\alpha$ in the lung tissue were higher than the control group. In addition, in AP rats modeled after $3 \mathrm{~h}, 6 \mathrm{~h}$ and $12 \mathrm{~h}$, the serum concentration of $\mathrm{H}_{2} \mathrm{~S}$ was higher than the control group. These results demonstrate that the $\mathrm{H}_{2} \mathrm{~S}$ / CSE system is up-regulated in APALI. After intraperitoneal injection of PAG, CSE mRNA expression was suppressed, the serum concentration of $\mathrm{H}_{2} \mathrm{~S}$ was reduced, and the pathology index of the lung was reduced. Based on these data, we conclude that the $\mathrm{H}_{2} \mathrm{~S} / \mathrm{CSE}$ system may aggravate APALI 
and a CSE inhibitor could be employed to reduce the pulmonary inflammation and injury. However, after $12 \mathrm{~h}$, there was no significant difference between AP and PAG rats in CSE and TNF- $\alpha$ expression but there was in $\mathrm{H}_{2} \mathrm{~S}$ levels, which may suggest that $\mathrm{H}_{2} \mathrm{~S}$ has a longer half-life and a different release rate compared to CSE/TNF- $\alpha$ in the body. We will address this in our future investigations.

Interestingly, in this study we found that the expression pattern of CSE was parallel to that of TNF- $\alpha$ in AP rats and PAG-treated AP rats. These findings suggest that TNF- $\alpha$ may play an important role in mediating $\mathrm{H}_{2} \mathrm{~S}$-induced APALI. Paria et al. found that TNF- $\alpha$ induced transient receptor potential channel-1 (TRPC-1) to increase the intracellular $\mathrm{Ca}^{2+}$ concentration in endothelial cells via activation of the NF- $\kappa B$ pathway [22]. The activation of NF- $\kappa \mathrm{B}$ has been implicated in lung microvascular injury induced by LPS and it plays an important role in sepsis-induced liver injury in rats [23, 24]. Further studies are important to elucidate the exact mechanism by which TNF- $\alpha$ mediates $\mathrm{H}_{2} \mathrm{~S}$-induced APALI.

In conclusion, in the present study we demonstrate that the serum concentrations of $\mathrm{H}_{2} \mathrm{~S}$ and CSE and TNF- $\alpha$ expression in the lung were increased in rats with AP. Intraperitoneal injection of the CSE inhibitor PAG could reduce the serum concentration of $\mathrm{H}_{2} \mathrm{~S}$ and alleviate the lung pathology. These results suggest that the $\mathrm{H}_{2} \mathrm{~S} / \mathrm{CSE}$ system is crucially involved in the pathological process of APALI and represents a novel target for the therapy of APALI.

\section{Acknowledgments}

We thank Dr. Dong Zhang and Dr. Jian-Sheng Zhou for their helpful discussions. This study was supported byScience and Technology Projects Grant CY20119002, Changzhou Science and Technology Bureau of China.

\section{References}

1. Bai Y, Liu Y, Jia L, et al. Severe acute pancreatitis in China: etiology and mortality in 1976 patients. Pancreas 2007; 35: 232-7.

2. Lytras D, Manes K, Triantopoulou C, et al. Persistent early organ failure: defining the high-risk group of patients with severe acute pancreatitis? Pancreas 2008; 36: 249-54.

3. Hirota M, Nozawa F, Okabe A, et al. Relationship between plasma cytokine concentration and multiple organ failure in patients with acute pancreatitis. Pancreas 2000; 21: 141-6.

4. Bhatia M, Wong FL, Fu D, Lau HY, Moochhala SM, Moore PK. Role of hydrogen sulfide in acute panereatitis and associated lung injury. FASEB J 2005; 19: 623-5.

5. Tamizhselvi R, Moore PK, Bhatia M. Hydrogen sulfide acts as a mediator of inflammation in acute pancreatitis: in vitro studies using isolated mouse pancreatic acinar cells. J Cell Mol Med 2007; 11: 315-26.

6. Koksel O, Yildirim C, Cinel L, et al. Inhibition of poly (ADP-ribose) polymerase attenuates lung tissue dam- age after hind limb ischemia-reperfusion in rats. Pharmacol Res 2005; 51: 453-62.

7. Perna AF, Luciano MG, Ingrosso D, et al. Hydrogen sulphide-generating pathways in haemodialysis patients: a study on relevant metabolites and transcriptional regulation of genes encoding for key enzymes. Nephrol Dial Transplant 2009; 24: 3756-63.

8. Oh GS, Pae HO, Lee BS, et al. Hydrogen sulfide inhibits nitric oxide production and Nuclear factor-kappaB via heme oxygenase-l expression jn RAW264.7 macrophages stimulated with lipopolysaccharide. Free Radic Biol Med 2006; 41: 106-19.

9. Zhang XP, Tian H, Wu DJ, et al. Pathological changes in multiple organs of rats with severe acute pancreatitis treated by baicalin and octreotide. Hepatobiliary Pancreat Dis Int 2009; 8: 85-92.

10. ZhaoW, Zhang J, Lu Y, Wang R. The vasorelaxant effect of $\mathrm{H} 2 \mathrm{~S}$ as anovel endogenous gaseous KATP channel opener. EMBO J 2001; 20: 6008-16.

11. Cheng Y, Ndisang JF, Tang G, Cao K, Wang R. Hydrogen sulfide induced relaxation of resistance mesenteric artery beds of rats. Heart Circ Physiol 2004; 287: 2316-23.

12. Busse R, Edwards G, Feketou M. EDHF: bring the concepts together. Trends Pharmacol Sci 2002; 23: 374-80.

13. ZhaoW, Wang R. H2S induced vasorelaxation and underlying cellular and molecular mechanisms. Am J Physiol Heart CircPhysiol 2002; 283: 474-80.

14. Baskar R, Li L, Moore PK. Hydrogen sulfide-induces DNA damage and changes in apoptotic gene expression in human lung fibroblast cells. FASEB J 2007; 21: 247-55.

15. Zagli G, Patacchini R, Trevisani M, et al. Hydrogen sulfide inhibits human platelet aggregation. Eur J Pharmacol 2007; 559: 65-8

16. Zhang H, Zhi L, Moochhala S, Moore PK, Bhatia M. Hydrogen sulfide acts as an inflammatory mediator in cecal ligation and puncture induced sepsis in mice by up regulating the production of cytokines and chemokines via NF-kappaB. Am J Physiol Lung Cell Mol Physiol 2007; 292: L960-71.

17. Pan TT, Feng ZN, Lee SW, Moore PK, Bian JS. Endogenous hydrogen sulfide contributes to the cardio protection by metabolic inhibition preconditioning in the rat ventricular myocytes. J Mol Cell Cardiol 2006; 40: 119-30.

18. Wei P, Zhou XH, Ling YQ, Huang XL, Ling YL. The role of hydrogen sulfide in lipopolysaccharide-induced acute lung injury. Basic Clin Med 2006; 26: 306-11.

19. Zhang X, Geng B, Zhang ZG, et al. The role of gaseous molecules hydrogen sulfide in oleic acid induced acute lung injury. J Cardiovasc Pulmon Dis 2007; 26: 108-21.

20. Li L, Bhatia M, Zhu YZ, et al. Hydrogen sulfide is a novel mediator of lipopolysaccharide- induced inflammation in the mouse. FASEB J 2005; 19: 1196-8.

21. Bhatia M, Sidhapuriwala JN, Ng SW, Tamizhselvi R, Moochhala SM. Pro-inflammatory effects of hydrogen sulphide on substance $P$ in caerulein-induced acute pancreatitis. J Cell Mol Med 2008; 12: 580-90.

22. Paria BC, Malik AB, Kwiatek AM, et al. Tuner necrosis actor-alpha induces nuclear factor-kappaB-dependent TRPC1 expression in endothelial cells. Biol Chem 2003; 278: 37195-203.

23. Liu Z, Yu Y, Jiang Y, Li J. Growth hormone increases lung NF-kappaB activation and lung microvascular injury induced by lipopolysaccharide in rats. Ann Clin Lab Sci 2002; 32: 164-70.

24. Sun WC, Pei L. Ozone preconditioning and exposure to ketamine attenuates hepatic inflammation in septic rats. Arch Med Sci 2012; 5: 918-23. 